\title{
Optic disc size and progression of visual field damage in patients with normal-tension glaucoma
}

This article was published in the following Dove Press journal:

Clinical Ophthalmology

2 May 2013

Number of times this article has been viewed

\section{Fukuko Hayamizu \\ Yoshio Yamazaki \\ Takako Nakagami \\ Kenji Mizuki}

Department of Ophthalmology, Division of Visual Science, Nihon University School of Medicine, Tokyo, Japan
Correspondence: Yoshio Yamazaki Department of Ophthalmology, Division of Visual Science, Nihon University School of Medicine, 30-I Oyaguchikamimachi, Itabashi-ku, Tokyo I73-86I0, Japan $\mathrm{Tel}+8$ I 33972 8I II

Fax +8I 359953495

Email yamazaki.yoshio@nihon-u.ac.jp
Purpose: Our goal was to evaluate the influence of optic disc size on the progression of visual field damage in patients with normal-tension glaucoma (NTG).

Subjects and methods: Eighty-two eyes of 82 NTG patients who had been receiving topical antiglaucoma medications and followed-up for more than 4 years were enrolled in this study. The patients were allocated to two groups, according to the mean size of their optic discs. The data were analyzed using regression analysis, based on the Cox proportional hazard model.

Results: The probability of visual field stability was significantly lower in eyes with large discs than in those with small discs ( $\log$ rank test, $P=0.007)$. Progression of visual field damage was significantly associated with the optic disc area (hazard ratio [HR]: 1.812, $P=0.018$ ), occurrence of disc hemorrhage (HR: $2.116, P=0.028$ ), and intraocular pressure reduction ratio (HR: $0.957, P=0.014$ ).

Conclusion: The optic disc area correlates with progression of visual field damage in patients with NTG.

Keywords: Cox proportional hazards model, disc hemorrhage, disc size, intraocular pressure, Kaplan-Meier life-table analysis

\section{Introduction}

Optic disc size is reportedly a possible risk factor for glaucomatous optic nerve damage. ${ }^{1-5}$ However, some groups have reported no difference in susceptibility between large and small discs. ${ }^{6-11}$ Thus, the relationship between the size of the optic disc and glaucomatous optic nerve damage is still controversial.

Most previous studies based assessment of optic disc size on fundus photographs. Measurement of optic disc size by planimetry is inaccurate because it is subjective and, therefore, varies among observers. As for the progression of visual field damage, Chauhan et $\mathrm{al}^{12}$ reported that the detection of small gradual changes requires lengthy follow-up. In addition, frequent examinations per year are required for accurate assessment. Thus, both lengthy and frequent follow-ups are necessary to evaluate progressive changes in visual fields accurately. To the best of our knowledge, there are no published clinical reports evaluating the relationship between optic disc size as determined by confocal scanning laser ophthalmoscopy and progression of visual field damage in patients with normal-tension glaucoma (NTG). The purpose of this study was to investigate the relationship between the size of the optic disc and progression of visual field damage in patients with NTG. 


\section{Subjects and methods Subjects}

We retrospectively reviewed the records of 313 patients with NTG attending the Glaucoma Clinic of the Department of Ophthalmology, Nihon University Hospital, to identify patients suitable for inclusion in this study. We defined NTG as normal open angle; peak intraocular pressure (IOP) $\leq 21 \mathrm{mmHg}$ at all times, including 24-hour phasing; presence of typical glaucomatous visual field damage associated with glaucomatous optic nerve changes; and the presence of optic neuropathy not attributable to other ocular or systemic disease. ${ }^{13}$ The Ethics Review Committee of the Nihon University School of Medicine approved the protocol of the study. All patients selected for this study gave written informed consent.

\section{Inclusion criteria}

From 313 patients with NTG whose records we reviewed, we selected patients for further assessment according to the following criteria: (1) best-corrected visual acuity $\geq 20 / 25$ at the beginning and end of the follow-up period; (2) spherical equivalent $\geq-6$ diopters; (3) no history of intraocular or laser surgery; (4) no tilted disc and vertical/horizontal ratio of the optic disc $<6 / 5$; (5) initial mean deviation of $-20 \mathrm{~dB}$ or better; and (6) a follow-up period of at least 4 years after the diagnosis with reliable results of the visual field examinations at least nine times in addition to the initial examination. If the patient had undergone surgical treatment, we analyzed only the preoperative data. When both eyes of a patient met the above criteria, we selected the findings for the right eye. We included 82 eyes of 82 NTG patients in the current study.

\section{Ophthalmic examinations}

After washing out topical antiglaucoma medications for 4 weeks, all enrolled patients were hospitalized to undergo testing for diurnal IOP variations with a Goldmann applanation tonometer (Haag-Streit, Koeniz, Switzerland). We took IOP measurements every 2 hours from 06.00 to 24.00 hours. Ophthalmological examinations included assessment of refraction, axial-length, central corneal thickness, and visual field examinations using the central 30-2 program with the Humphrey Field Analyzer (HFA 30-2; Carl Zeiss Meditec, Dublin, CA, USA). The criteria for a reliable visual field examination were $\leq 33 \%$ for both false-positive and false-negative findings and $<20 \%$ for fixation loss. We took optic disc stereo photographs with a stereo fundus camera (3-DX, NIDEK, Gamagori, Japan) and performed three-dimensional topographic analysis of the optic disc with a Heidelberg Retina Tomograph (HRT) (HRT version 2.01; Heidelberg Engineering GmbH, Heidelberg, Germany) when appropriate. We constructed mean topographic images obtained from more than five images using the HRT. While viewing the optic disc stereo photograph, two experienced operators (YY, FH) drew the contour line of the optic disc margin at the inner edge of the scleral ring on the HRT screen using a computer mouse. The mean HRT topographic images with standard deviation $<40 \mu \mathrm{m}$ were used in the present study.

\section{Follow-up}

After the above-described initial assessment, all patients visited the clinic for IOP measurement and evaluation of optic disc changes every $8-12$ weeks. We performed visual field examinations with the HFA 30-2 program every 6 months.

\section{Criteria for progression of visual field damage}

We defined progression of visual field damage according to the criteria of the Collaborative Normal Tension Glaucoma Study Group (CNTGS). ${ }^{14}$ These criteria are as follows: (1) two or more points that have deteriorated by at least $10 \mathrm{~dB}$ from the average baseline values for those points. These two progressing points must be adjacent, both cannot be peripheral, and they are not to cross the nasal meridian; and (2) at least one of the innermost four points shows at least a $10 \mathrm{~dB}$ deterioration from the average baseline value. We considered progression to be confirmed when four of five consecutive follow-up fields showed progression relative to baseline fields, with at least one nonperipheral progressing point (or the one central point) being common to all four fields.

\section{Analysis of findings}

We divided the enrolled subjects into two groups, according to the mean size of their optic discs as assessed by HRT. We compared the clinical background data of patients' eyes with small versus large disc areas and of those with progressive versus without progressive visual field damage. We also compared visual field stability in the two groups using the Kaplan-Meier life-table analysis.

In addition, we analyzed the influence of various clinical factors on the progression of visual field damage by regression analysis of patient data based on the Cox proportional hazards model. The factors thus analyzed included patient age, sex, mean deviation, and corrected pattern standard deviation, refraction, central corneal thickness, axial length, disc size, occurrence of disc hemorrhage (DH), combina- 
tion of antiglaucoma agents, mean IOP of diurnal variation, mean IOP during follow-up, and the IOP reduction ratio. We defined the IOP reduction ratio as:

(Mean IOP of diurnal variation - Mean IOP during follow-up)/Mean IOP of diurnal variation $\times 100(\%)$. (1)

Differences between the means were considered to be significant at $P<0.05$, determined using the Statistical Package for the Social Sciences 17.0 (SPSS, IBM Corporation, Armonk, NY, USA). We did not evaluate details of compliance with medications.

\section{Results}

Table 1 shows the clinical background data. Because the mean optic disc area as determined by HRT was $2.41 \mathrm{~mm}^{2}$ overall, we set the cut-off value for optic disc area at $2.41 \mathrm{~mm}^{2}$. Figure 1 shows the distribution curve of the optic

Table I Clinical data for all enrolled subjects $(n=82)$

\begin{tabular}{|c|c|c|}
\hline Age (years) & $58.0 \pm 9.3$ & $(33-74)$ \\
\hline Sex (number, male/female) & $34 / 48$ & \\
\hline Duration of follow-up (months) & $103 \pm 29$ & $(5 I-173)$ \\
\hline MD (decibels) & $-8.7 \pm 5.2$ & $(-19.9$ to 0.5$)$ \\
\hline CPSD (decibels) & $9.9 \pm 4.6$ & $(2.1-18.6)$ \\
\hline Refraction (diopters) & $-I . I \pm 2.4$ & $(-6.0$ to 3.0$)$ \\
\hline CCT (mm) & $0.50 \pm 0.04$ & $(0.42-0.66)$ \\
\hline Axial length $(\mathrm{mm})$ & $23.8 \pm 1.3$ & $(2 I . I-26.6)$ \\
\hline Disc area $\left(\mathrm{mm}^{2}\right)$ & $2.41 \pm 0.57$ & $(1.30-3.82)$ \\
\hline DH (number, positive/negative) & $19 / 63$ & \\
\hline Number of antiglaucoma agents & $1.7 \pm 0.7$ & $(I-3)$ \\
\hline \multicolumn{3}{|l|}{ IOP of diurnal variation $(\mathrm{mmHg})$} \\
\hline Mean & $13.7 \pm 1.9$ & $(8.8-17.9)$ \\
\hline Maximum & $16.4 \pm 2.2$ & $(|2.0-2| .0)$ \\
\hline Minimum & $11.0 \pm 2.0$ & $(6.0-16.0)$ \\
\hline \multicolumn{3}{|l|}{ IOP during follow-up (mmHg) } \\
\hline Mean & $13.0 \pm 1.6$ & $(9.4-16.4)$ \\
\hline Maximum & $16.3 \pm 2.2$ & $(|2.0-2| .0)$ \\
\hline Minimum & $9.9 \pm 1.6$ & $(6.0-14.0)$ \\
\hline IOP reduction ratio (\%) & $4.2 \pm 9.8$ & $(-20.6$ to 29.0$)$ \\
\hline \multicolumn{3}{|c|}{ Prevalence of receiving topical medications during follow-up } \\
\hline PG & 11 & \\
\hline Al & 29 & \\
\hline CAI & I & \\
\hline $\mathrm{PG}+\mathrm{Al}$ & 27 & \\
\hline $\mathrm{PG}+\mathrm{CAI}$ & 3 & \\
\hline $\mathrm{Al}+\mathrm{CAl}$ & 4 & \\
\hline$P G+A I+C A I$ & 7 & \\
\hline
\end{tabular}

Notes: Values are presented as mean \pm standard deviation (range). IOP reduction ratio $=($ mean IOP of diurnal variation - mean IOP during follow-up)/mean IOP of diurnal variation $\times 100$.

Abbreviations: $n$, number; MD, mean deviation; CPSD, corrected pattern standard deviation; CCT, central corneal thickness; $\mathrm{DH}$, occurrence of disc hemorrhage; IOP, intraocular pressure; PG, prostaglandins; AI, adrenergic inhibitors $(\alpha, \beta)$; $\mathrm{CAl}$, carbonic anhydrase inhibitors.

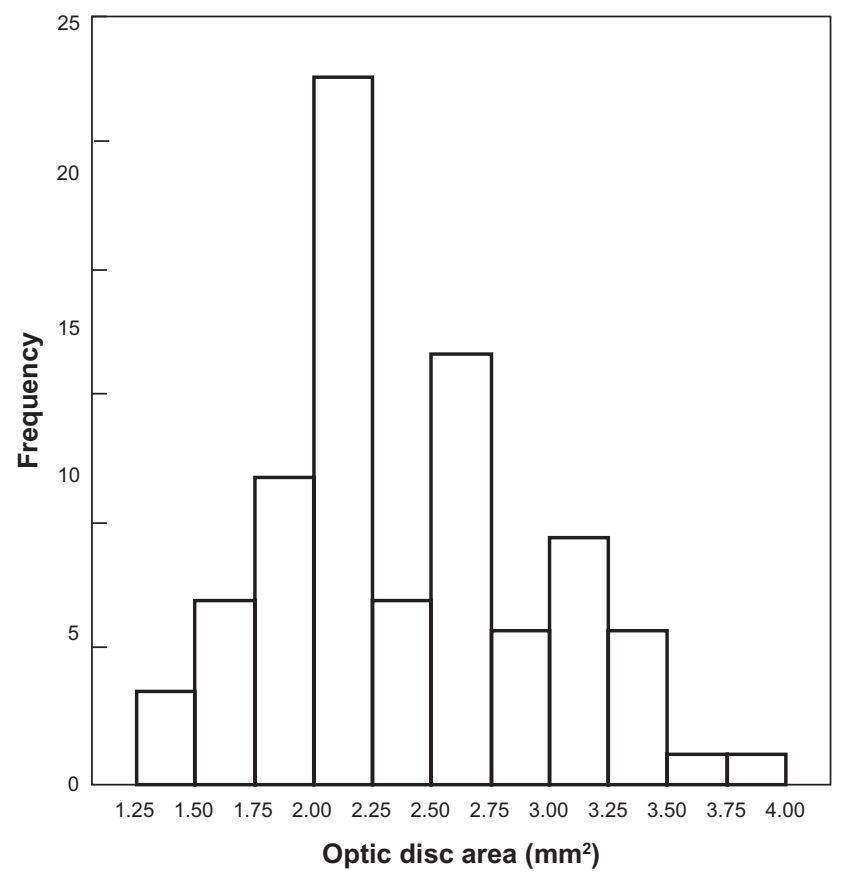

Figure I Distribution of optic disc area for all subjects.

Notes: Mean value was $2.41 \mathrm{~mm}^{2}$ and standard deviation was $0.57 \mathrm{~mm}^{2}$ (range: $1.30 \mathrm{~mm}^{2}$ to $3.82 \mathrm{~mm}^{2}$ ).

disc area of the 82 eyes. The mean value for optic disc area in this study corresponded to previously reported values for normal eyes. ${ }^{15,16}$ The mean follow-up time for all patients was $103 \pm 30$ months (mean \pm standard deviation). Of the 82 patients enrolled in this study, 43 reached the end-point during follow-up, and the probability of visual field stability was $47 \% \pm 6 \%$ in all patients.

We divided the 82 enrolled patients into the following two groups, according to the mean optic disc area $\left(2.41 \mathrm{~mm}^{2}\right) ; 38$ patients with large discs and 44 with small discs. Table 2 shows clinical background data for eyes with large versus small disc areas. There were no statistically significant differences in these data apart from optic disc area. There were no significant differences in the number of patients receiving topical antiglaucoma medications during follow-up. Of the 38 eyes with large disc areas, $26(68 \%)$ showed progression of visual field damage and 12 (32\%), no progression. Of the 44 eyes with a small disc area, 17 (39\%) showed progression of visual field damage, whereas 27 (61\%) showed no progression. Figure 2 shows the KaplanMeier curve for the probability of visual field stability. The probability of visual field stability was $36 \% \pm 8 \%$ for eyes with large disc areas and $56 \% \pm 8 \%$ for those with small disc areas. There was a statistically significant difference in the probability of visual field stability between eyes with large versus small disc areas (log rank test, $P=0.007)$. 
Table 2 Clinical data for eyes with large versus small discs

\begin{tabular}{|c|c|c|c|}
\hline Variable & $\begin{array}{l}\text { Eyes with } \\
\text { large disc } \\
\text { area }(n=38)\end{array}$ & $\begin{array}{l}\text { Eyes with } \\
\text { small disc } \\
\text { area }(n=44)\end{array}$ & $P$-value \\
\hline Age (years) & $57.17 \pm 9.6$ & $58.7 \pm 9.1$ & $\mathrm{~ns}^{\dagger}$ \\
\hline $\begin{array}{l}\text { Sex (number, } \\
\text { male/female) }\end{array}$ & $16 / 22$ & $18 / 26$ & $\mathrm{~ns}^{\ddagger}$ \\
\hline $\begin{array}{l}\text { Duration of follow-up } \\
\text { (months) }\end{array}$ & $102 \pm 30$ & $103 \pm 28$ & $\mathrm{~ns}^{\dagger}$ \\
\hline MD (decibels) & $-8.8 \pm 4.8$ & $-8.7 \pm 5.5$ & $\mathrm{~ns}^{\dagger}$ \\
\hline CPSD (decibels) & $9.2 \pm 4.8$ & $10.4 \pm 4.4$ & $\mathrm{~ns}^{\dagger}$ \\
\hline Refraction (diopters) & $-1.5 \pm 2.5$ & $-0.8 \pm 2.3$ & $\mathrm{~ns}^{\dagger}$ \\
\hline CCT (mm) & $0.50 \pm 0.04$ & $0.49 \pm 0.03$ & $\mathrm{~ns}^{\dagger}$ \\
\hline Axial length (mm) & $24.1 \pm 1.3$ & $23.6 \pm 1.3$ & $\mathrm{~ns}^{\dagger}$ \\
\hline Disc area $\left(\mathrm{mm}^{2}\right)$ & $2.91 \pm 0.37$ & $1.98 \pm 0.26$ & $0.000^{\dagger}$ \\
\hline $\begin{array}{l}\text { DH (number, } \\
\text { positive/negative) }\end{array}$ & $10 / 28$ & $9 / 35$ & $\mathrm{~ns}^{\dagger}$ \\
\hline $\begin{array}{l}\text { Number of } \\
\text { antiglaucoma agents }\end{array}$ & $1.7 \pm 0.8$ & $1.7 \pm 0.6$ & $\mathrm{~ns}^{\dagger}$ \\
\hline \multicolumn{4}{|c|}{ IOP of diurnal variation $(\mathrm{mmHg})$} \\
\hline Mean & $13.5 \pm 1.9$ & $13.9 \pm 1.8$ & $\mathrm{~ns}^{\dagger}$ \\
\hline Maximum & $16.1 \pm 2.5$ & $16.7 \pm 2.0$ & $\mathrm{~ns}^{\dagger}$ \\
\hline Minimum & $10.8 \pm 2.0$ & $11.2 \pm 2.0$ & $\mathrm{~ns}^{\dagger}$ \\
\hline \multicolumn{4}{|c|}{ IOP during follow-up $(\mathrm{mmHg})$} \\
\hline Mean & $12.9 \pm 1.7$ & $13.2 \pm 1.6$ & $\mathrm{~ns}^{\dagger}$ \\
\hline Maximum & $16.1 \pm 2.2$ & $16.4 \pm 2.1$ & $\mathrm{~ns}^{\dagger}$ \\
\hline Minimum & $9.7 \pm 1.8$ & $10.1 \pm 1.5$ & $\mathrm{~ns}^{\dagger}$ \\
\hline $\begin{array}{l}\text { IOP reduction } \\
\text { ratio (\%) }\end{array}$ & $4.1 \pm 10.0$ & $4.6 \pm 9.8$ & $\mathrm{~ns}^{\dagger}$ \\
\hline $\begin{array}{l}\text { Progression of visual } \\
\text { field damage } \\
\text { (positive/negative) }\end{array}$ & $26 / 12$ & $17 / 27$ & $0.009 \ddagger$ \\
\hline $\begin{array}{l}\text { Prevalence of receiving } \\
\text { topical medications } \\
\text { during follow-up }\end{array}$ & & & $0.30 \mathrm{I}^{\ddagger}$ \\
\hline PG & 5 & 6 & \\
\hline $\mathrm{Al}$ & 16 & 13 & \\
\hline CAI & 1 & 0 & \\
\hline $\mathrm{PG}+\mathrm{Al}$ & 8 & 19 & \\
\hline$P G+C A I$ & I & 2 & \\
\hline $\mathrm{Al}+\mathrm{CAl}$ & 3 & 1 & \\
\hline $\mathrm{PG}+\mathrm{Al}+\mathrm{CAl}$ & 4 & 3 & \\
\hline
\end{tabular}

Notes: Values are presented as mean \pm standard deviation; †unpaired Student's

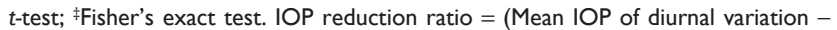
Mean IOP during follow-up)/Mean IOP of diurnal variation $\times 100$.

Abbreviations: $n$, number; ns, not significant; MD, mean deviation; CPSD, corrected pattern standard deviation; CCT, central corneal thickness; $\mathrm{DH}$, occurrence of disc hemorrhage; IOP, intraocular pressure; PG, prostaglandins; Al, adrenergic inhibitors $(\alpha, \beta)$; CAI, carbonic anhydrase inhibitors.

Table 3 shows clinical background data for eyes with and without progressive visual field damage. There were statistically significant differences in the sizes of the disc areas ( $P=0.009$, unpaired Student's $t$-test) and occurrence of DH $(P=0.010$, Fisher's exact test $)$. There were no significant differences in the number of patients receiving topical antiglaucoma medications during follow-up.

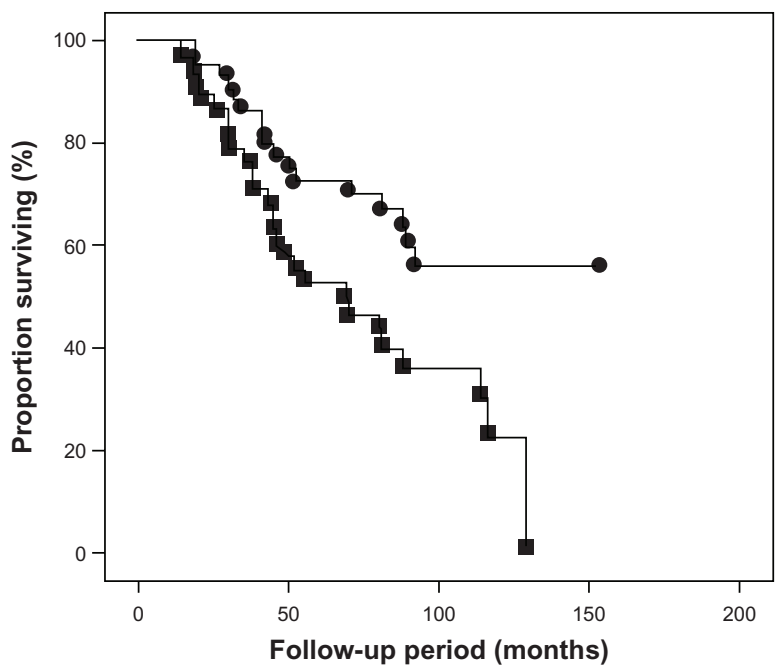

Figure 2 The probability of visual field stability, according to optic disc size. Notes: $\bullet$, eyes with small discs; $\boldsymbol{\square}$, eyes with large discs. There is a statistically significant difference in the probability of visual field damage between eyes with small discs and those with large discs at 102 months. $P=0.007$ (log rank test).

In the 82 eyes in this study, the Cox proportional hazards model indicated that the optic disc areas (hazard ratio [HR]: $1.812, P=0.018$ ), occurrence of DH (HR: 2.116, $P=0.028$ ), and IOP reduction ratio (HR: $0.957, P=0.014$ ) were significantly correlated with progression of visual field damage (Table 4).

\section{Discussion}

Our study demonstrated that eyes with large disc areas have a significantly greater incidence of progressive visual field defects than do those with small disc areas. This finding suggests that large optic discs within the normal range of IOP are susceptible to glaucomatous damage, in accordance with previous reports. ${ }^{1-3}$ Nesterov and Egorov documented that the size of the optic disc has a sensitive relationship with IOP, because the lamina cribrosa has a multilayer spring system. ${ }^{17}$ Recently, researchers reported that eyes with NTG have a significantly thinner lamina cribrosa than do those with primary open-angle glaucoma and matched visual field defects as assessed by the enhanced depth-imaging mode of optical coherence tomography. ${ }^{18}$ These findings suggest that large optic discs are structurally weak. This may increase their susceptibility for the development of glaucomatous damage at any given level of IOP.

Based on the membrane theory of a mathematical model, Chi et $\mathrm{a}^{19}$ reported that the lamina cribrosa of large discs undergoes significant displacement in the presence of a high IOP. Bellezza et $\mathrm{al}^{20}$ have categorized the optic disc as a biomechanical structure. Their paradigm suggests that mechanical failure of the connective tissue of the lamina 
Table 3 Clinical data for eyes with and without progressive visual field damage

\begin{tabular}{|c|c|c|c|}
\hline Variable & $\begin{array}{l}\text { Eyes with } \\
\text { progressive } \\
\text { visual field } \\
\text { damage } \\
(n=43)\end{array}$ & $\begin{array}{l}\text { Eyes without } \\
\text { progressive } \\
\text { visual field } \\
\text { damage } \\
(n=39)\end{array}$ & $P$-value \\
\hline Age (years) & $57.2 \pm 9.9$ & $58.8 \pm 8.7$ & $\mathrm{~ns}^{\dagger}$ \\
\hline $\begin{array}{l}\text { Sex (number, } \\
\text { male/female) }\end{array}$ & $16 / 27$ & $18 / 21$ & $\mathrm{~ns}^{\ddagger}$ \\
\hline $\begin{array}{l}\text { Duration of follow-up } \\
\text { (months) }\end{array}$ & $105 \pm 30$ & $100 \pm 28$ & $\mathrm{~ns}^{\dagger}$ \\
\hline MD (decibels) & $-8.7 \pm 4.5$ & $-8.8 \pm 5.8$ & $\mathrm{~ns}^{\dagger}$ \\
\hline CPSD (decibels) & $10.0 \pm 4.5$ & $9.7 \pm 4.8$ & $\mathrm{~ns}^{\dagger}$ \\
\hline Refraction (diopters) & $-1.4 \pm 2.5$ & $-0.8 \pm 2.2$ & $\mathrm{~ns}^{\dagger}$ \\
\hline CCT (mm) & $0.50 \pm 0.03$ & $0.49 \pm 0.05$ & $\mathrm{~ns}^{\dagger}$ \\
\hline Axial length (mm) & $23.9 \pm 1.4$ & $23.7 \pm 1.2$ & $\mathrm{~ns}^{\dagger}$ \\
\hline Disc area $\left(\mathrm{mm}^{2}\right)$ & $2.57 \pm 0.57$ & $2.25 \pm 0.52$ & $0.009^{\dagger}$ \\
\hline $\begin{array}{l}\text { DH (number, } \\
\text { positive/negative) }\end{array}$ & $15 / 28$ & $4 / 35$ & $0.010^{\ddagger}$ \\
\hline $\begin{array}{l}\text { Number of } \\
\text { antiglaucoma agents }\end{array}$ & $1.6 \pm 0.7$ & $1.7 \pm 0.7$ & $\mathrm{~ns}^{\dagger}$ \\
\hline \multicolumn{4}{|c|}{ IOP of diurnal variation $(\mathrm{mmHg})$} \\
\hline Mean & $13.6 \pm 1.6$ & $13.8 \pm 2.1$ & $\mathrm{~ns}^{\dagger}$ \\
\hline Maximum & $16.3 \pm 2.0$ & $16.6 \pm 2.4$ & $\mathrm{~ns}^{\dagger}$ \\
\hline Minimum & $10.8 \pm 1.7$ & $11.2 \pm 2.3$ & $\mathrm{~ns}^{\dagger}$ \\
\hline \multicolumn{4}{|c|}{ IOP during follow-up (mmHg) } \\
\hline Mean & $13.1 \pm 1.6$ & $12.9 \pm 1.7$ & $\mathrm{~ns}^{\dagger}$ \\
\hline Maximum & $16.2 \pm 2.1$ & $16.5 \pm 2.3$ & $\mathrm{~ns}^{\dagger}$ \\
\hline Minimum & $10.0 \pm 1.8$ & $9.8 \pm 1.6$ & $\mathrm{~ns}^{\dagger}$ \\
\hline $\begin{array}{l}\text { IOP reduction } \\
\text { ratio }(\%)\end{array}$ & $3.1 \pm 10.2$ & $5.1 \pm 9.3$ & $\mathrm{~ns}^{\dagger}$ \\
\hline $\begin{array}{l}\text { Prevalence of receiving } \\
\text { topical medications } \\
\text { during follow-up }\end{array}$ & & & $0.700^{\ddagger}$ \\
\hline$P G$ & 5 & 6 & \\
\hline Al & 17 & 12 & \\
\hline CAI & 1 & 0 & \\
\hline $\mathrm{PG}+\mathrm{Al}$ & II & 16 & \\
\hline $\mathrm{PG}+\mathrm{CAI}$ & 2 & I & \\
\hline$A I+C A I$ & 3 & I & \\
\hline $\mathrm{PG}+\mathrm{Al}+\mathrm{CAI}$ & 4 & 3 & \\
\hline
\end{tabular}

Notes: Values are presented as mean \pm standard deviation; 'unpaired Student's

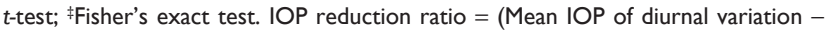
Mean IOP during follow-up)/Mean IOP of diurnal variation $\times 100$.

Abbreviations: $\mathrm{n}$, number; $\mathrm{ns}$, not significant; MD, mean deviation; CPSD, corrected pattern standard deviation; CCT, central corneal thickness; $\mathrm{DH}$, occurrence of disc hemorrhage; IOP, intraocular pressure; PG, prostaglandins; $\mathrm{Al}$, adrenergic inhibitors $(\alpha, \beta)$; CAl, carbonic anhydrase inhibitors.

cribrosa underlies glaucomatous cupping, and they postulate that larger discs are more susceptible to IOP-related stress, in accordance with Laplace's law. ${ }^{20}$ These reports suggest that, in eyes with NTG, the organizational structure of optic discs determines their susceptibility to increased IOP. Because larger optic discs have structures that are more vulnerable to the deleterious effects of increased IOP, they are more susceptible to glaucomatous optic neuropathy.
Table 4 Factors identified as associated with progression of visual field damage in patients with NTG $(n=82)$

\begin{tabular}{llll}
\hline Factors & $\begin{array}{l}\text { Hazard } \\
\text { ratio }\end{array}$ & $\begin{array}{l}\text { 95\% confidence } \\
\text { interval }\end{array}$ & P-value \\
\hline $\begin{array}{l}\text { Disc area by I } \mathrm{mm}^{2} \\
\text { increase }\end{array}$ & 1.812 & $1.110-2.961$ & 0.018 \\
Occurrence of disc hemorrhage & & \\
$\quad$ Absence & $\mathrm{I}$ & & \\
$\quad$ Presence & 2.116 & $1.082-4.136$ & 0.028 \\
IOP reduction ratio & 0.957 & $0.925-0.991$ & 0.014 \\
by I\% increase & & & \\
\hline
\end{tabular}

Note: IOP reduction ratio $=($ Mean IOP of diurnal variation - Mean IOP during follow-up)/Mean IOP of diurnal variation $\times 100$.

Abbreviations: NTG, normal-tension glaucoma; n, number; IOP, intraocular pressure.

The present study shows that progression of visual field damage correlates significantly with the IOP reduction ratio. IOP is probably the only treatable factor in glaucoma. Many investigators have reported a relationship between increased IOP and the progression of visual field damage. The $\mathrm{CNTGS}^{14}$ demonstrated that the probability of visual field stability at 5 years was $80 \%$ in a treated group that had filtering surgery and 35\% in an untreated group. Our study showed that the probability of visual field stability is $63 \%$ at 60 months and $47 \%$ at 103 months in patients receiving topical antiglaucoma medication. Thus, topical medication to reduce IOP is useful for preventing progression of visual field damage, even though the IOP reduction it achieves is not as great as that following filtration surgery.

Occurrence of $\mathrm{DH}$ is a well known predictor of progression of visual field damage in patients with NTG. ${ }^{21-23}$ The precise mechanism of DH has not been determined; however, it may result from regressive vascular changes after expansion of the width of retinal nerve fiber layer defects. ${ }^{24}$ Previously, Yamazaki et al ${ }^{13}$ reported that circulatory factors in the retrobulbar vessels may be associated with worsening of visual field damage in NTG patients. In our study, we found that the occurrence of $\mathrm{DH}$, which may be related to structural weakness or vascular disorders in the lamina cribrosa, correlates significantly with progression of visual field damage. However, we did not clarify the mechanism of DH in this study.

This study has some limitations. First, it is based on retrospective data; however, there were no significant differences in clinical background data, including the severity of visual field damage and IOP levels, between eyes with large and small disc areas during follow-up. Neither were there any differences between eyes with or without progressive visual field damage. Therefore, the size of the optic disc is a determinant of deterioration in glaucomatous optic neuropathy. 
Second, to obtain reliable data about optic disc configuration using HRT, we excluded patients with highly myopic eyes or oblique discs from this study because their range of refractive error was from $-8 \mathrm{D}$ to $+4 \mathrm{D} .{ }^{25}$ In HRT software version 2.01 , the reference plane is automatically set at $50 \mu \mathrm{m}$ posterior to the mean peripapillary retinal height along the contour line at the temporal sector between $350^{\circ}$ and $356^{\circ}$. However, because myopic discs are characteristically tilted from the nasal to the temporal side with the nasal margin elevated relative to the temporal margin, it is possible that this choice of reference plane accounts for the decreased capability of the HRT program in eyes with oblique discs. ${ }^{26}$ Therefore, we excluded highly myopic eyes and those with oblique discs from this study.

In conclusion, the present study revealed that the size of the optic disc is a definite risk factor for visual field deterioration in patients with NTG. Measurement of the optic disc area may be useful for predicting progressive visual field damage in patients with NTG. Further longitudinal studies are needed to investigate the relationship between the optic disc area and the progression of visual field damage in patients with glaucoma.

\section{Disclosure}

The authors report no conflicts of interest in this work.

\section{References}

1. Burk RO, Rohrschneider K, Noack H, Völcker HE. Are large optic nerve heads susceptible to glaucomatous damage at normal intraocular pressure? A three-dimensional study by laser scanning tomography. Graefes Arch Clin Exp Ophthalmol. 1992;230(6):552-560.

2. Tomita G, Nyman K, Raitta C, Kawamura M. Intraocular asymmetry of optic disc size and its relevance to visual field loss in normal-tension glaucoma. Graefes Arch Clin Exp Ophthalmol. 1994;232(5):290-296.

3. Tuulonen A, Airaksinen PJ. Optic disc size in exfoliative, primary open angle, and low-tension glaucoma. Arch Ophthalmol. 1992; 110(2):211-213.

4. Healey PR, Mitchell P. Optic disc size in open-angle glaucoma: the Blue Mountains Eye Study. Am J Ophthalmol. 1999;128(4):515-517.

5. Wang L, Damji KF, Munger R, et al. Increased disk size in glaucomatous eyes versus normal eyes in the Reykjavik eye study. Am J Ophthalmol. 2003;135(2):226-228.

6. Jonas JB, Fernandez MC, Naumann GO. Correlation of optic disc size to glaucoma susceptibility. Ophthalmology. 1991;98(5):675-680.

7. Jonas JB, Stürmer J, Papastathopoulos KI, Meier-Gibbsons F, Dichtl A. Optic disc size and optic nerve damage in normal pressure glaucoma. $\mathrm{Br}$ J Ophthalmol. 1995;79(12):1102-1105.

8. Zangwill LM, Weinreb RN, Beiser JM, et al. Baseline topographic optic disc measurements are associated with the development of primary openangle glaucoma: the Confocal Scanning Laser Ophthalmoscopy Ancillary Study to the Ocular Hypertension Treatment Study. Arch Ophthalmol. 2005;123(9):1188-1197.
9. Quigley HA, Varma R, Tielsch JM, Katz J, Sommer A, Gilbert DL. The relationship between optic disc area and open-angle glaucoma: the Baltimore Eye Study. J Glaucoma. 1999;8(6):347-352.

10. Jonas JB, Xu L, Zhang L, Wang Y, Wang Y. Optic disc size in chronic glaucoma: the Beijing eye study. Am J Ophthalmol. 2006;142(1): 168-170.

11. Jonas JB, Martus P, Horn FK, Jünemann A, Korth M, Budde WM. Predictive factors of the optic nerve head for development or progression of glaucomatous visual field loss. Invest Ophthalmol Vis Sci. 2004; 45(8):2613-2618.

12. Chauhan BC, Garway-Heath DF, Goñi FJ, et al. Practical recommendations for measuring rates of visual field change in glaucoma. $\mathrm{Br} J$ Ophthalmol. 2008;92(4):569-573.

13. Yamazaki Y, Drance SM. The relationship between progression of visual field defects and retrobulbar circulation in patients with glaucoma. $\mathrm{Am}$ J Ophthalmol. 1997;124(3):287-295.

14. [No authors listed]. Comparison of glaucomatous progression between untreated patients with normal-tension glaucoma and patients with therapeutically reduced intraocular pressures. Collaborative NormalTension Glaucoma Study. Am J Ophthalmol. 1998;126(4):487-497.

15. Jonas JB, Naumann GOH. The optic nerve: its embryology, histology, and morphology. In: Varma R, Spaeth GL, Parker KW, editors. The Optic Nerve in Glaucoma. Philadelphia, PA: Lippincott; 1993:3-26.

16. Uchida H, Yamamoto T, Araie M, et al. Topographic characteristics of the optic nerve head measured with scanning laser tomography in normal Japanese subjects. Jpn J Ophthalmol. 2005;49(6):469-476.

17. Nesterov AP, Egorov EA. Pathological physiology of primary openangle glaucoma. The optic nerve changes. In: Cairns JE, editor. Glaucoma. Orlando, FL: Grune and Stratton; 1986:369-393.

18. Park HY, Jeon SH, Park CK. Enhanced depth imaging detects lamina cribrosa thickness differences in normal tension glaucoma and primary open-angle glaucoma. Ophthalmology. 2012;119(1):10-20.

19. Chi T, Ritch R, Stickler D, Pitman B, Tsai C, Hsieh FY. Racial differences in optic nerve head parameters. Arch Ophthalmol. 1989; 107(6):836-839.

20. Bellezza AJ, Hart RT, Burgoyne CF. The optic nerve head as a biomechanical structure: initial finite element modeling. Invest Ophthalmol Vis Sci. 2000;41(10):2991-3000.

21. Ishida K, Yamamoto T, Sugiyama K, Kitazawa Y. Disk hemorrhage is a significantly negative prognostic factor in normal-tension glaucoma. Am J Ophthalmol. 2000;129(6):707-714.

22. Drance S, Anderson DR, Schulzer M; for Collaborative NormalTension Glaucoma Study Group. Risk factors for progression of visual field abnormalities in normal-tension glaucoma. Am J Ophthalmol. 2001;131(6):699-708.

23. Nakagami T, Yamazaki Y, Hayamizu F. Prognostic factors for progression of visual field damage in patients with normal-tension glaucoma. Jpn J Ophthalmol. 2006;50(1):38-43.

24. Nitta K, Sugiyama K, Higashide T, Ohkubo S, Tanahashi T, Kitazawa Y. Does the enlargement of retinal nerve fiber layer defects relate to disc hemorrhage or progressive visual field loss in normal-tension glaucoma? J Glaucoma. 2011;20(3):189-195.

25. Leung CK, Cheng AC, Chong KK, et al. Optic disc measurements in myopia with optical coherence tomography and confocal scanning laser ophthalmoscopy. Invest Ophthalmol Vis Sci. 2007;48(7):3178-3183.

26. Yamazaki Y, Yoshikawa K, Kunimatsu S, et al. Influence of myopic disc shape on the diagnostic precision of the Heidelberg Retina Tomograph. Jpn J Ophthalmol. 1999;43(5):392-397. 
Clinical Ophthalmology

\section{Publish your work in this journal}

Clinical Ophthalmology is an international, peer-reviewed journal covering all subspecialties within ophthalmology. Key topics include: Optometry; Visual science; Pharmacology and drug therapy in eye diseases; Basic Sciences; Primary and Secondary eye care; Patien Safety and Quality of Care Improvements. This journal is indexed on

PubMed Central and CAS, and is the official journal of The Society of Clinical Ophthalmology (SCO). The manuscript management system is completely online and includes a very quick and fair peer-review system, which is all easy to use. Visit http://www.dovepress.com/ testimonials.php to read real quotes from published authors. 